\title{
Pulmonary Artery Banding: the Electrocardiogram as an Aid in Selection of Patients for Operation*
}

\author{
STANLEY M. HIGASHINO AND ARTHUR J. MOSS
}

From The Department of Pediatrics, University of California Medical Center, Los Angeles, California, U.S.A

Banding of the pulmonary artery was first proposed by Muller and Dammann (1952). Since that time, the procedure has become increasingly popular for palliation of infants suffering from heart failure due to a large left-to-right ventricular shunt. The surgically created pulmonary artery obstruction reduces the amount of left-to-right shunt, relieves the high output of the left ventricle, and may prevent progressive pulmonary vascular disease (Dammann et al., 1961).

Suggested indications for the banding procedure are: (1) intractable heart failure in infants with large left-to-right ventricular shunts, (2) left-toright ventricular shunts associated with pulmonary vascular obstructive disease (to prevent further progression of the vascular disease), and (3) inoperable lesions in which a decrease of excessive pulmonary flow might reduce congestive heart failure.

Since reported figures of operative mortality remain at a high level of 10-40 per cent (Albert et al., 1961; Gammelgaard et al., 1961; Craig and Sirak, 1963; Goldblatt et al., 1965), reappraisal of the indications for use of this procedure seems warranted. The present retrospective investigation was undertaken to evaluate the electrocardiogram as an aid in the selection of candidates for operation.

\section{MATERIAL AND Methods}

The charts of 29 patients subjected to the banding procedure at the UCLA Medical Center during the past seven years were evaluated. All had left-to-right ventricular shunts with pulmonary hypertension and normally situated great vessels. Pre-operative evaluation included history, physical examination, electrocardiogram, and teleradiogram. The diagnosis was confirmed by cardiac catheterization or necropsy in all cases.

The age of the patients at the time of operation was 2 weeks to 2 years (Table I). All but 8 of the 29 patients

Received May 20, 1966.

* Supported by United States Public Health Service Grants. were 6 months or younger, and only 2 were over 1 year of age. Intractable heart failure was uniformly present.

Pre-operative right heart catheterization was performed in 26 instances via the right saphenous vein. All pressures were recordad by Statham strain gauge transducers and an Offner multichannel oscillograph. The pulmonary-systemic pressure ratio exceeded 75 per cent in 19 of 23 children in whom measurements were made. Blood oxygen saturations were determined by cuvette oximetry. Pulmonary-systemic flow ratios were calculated according to the following formula:

Systemic arterial $\mathrm{O}_{2}$ saturation-Right atrial $\mathrm{O}_{2}$ saturation $\star$. Left atrial $\mathrm{O}_{2}$ saturation-Pulmonary arterial $\mathrm{O}_{2}$ saturation

The pulmonary-systemic flow ratio was greater than $2 \cdot 0$ in 17 of 20 children. The pitfalls of flow estimations in infants with heart failure were recognized and will be discussed later. An associated patent ductus arteriosus was present in 8 infants, an atrial septal defect in 3, and an atrio-ventricular canal in 6 (Table II).

Electrocardiograms obtained within the week preceding operation were re-interpreted without knowledge of the diagnosis or clinical course of the patients. Criteria for chamber enlargement in this group of patients were based mainly on the values cited by Guntheroth (1965) as follows.

Right ventricular hypertrophy. 0-1 month: $\mathrm{R}$ wave greater than $25 \mathrm{~mm}$. in V1 or S wave greater than $12 \mathrm{~mm}$. in V6. 1-24 months: $R$ wave greater than $20 \mathrm{~mm}$. in $\mathrm{V} 1$ or $\mathrm{R} / \mathrm{S}$ ratio in V6 less than 1.

Left ventricular hypertrophy. 0-12 months: $\mathrm{R}$ wave greater than $30 \mathrm{~mm}$. in V5 or $21 \mathrm{~mm}$. in V6, S wave greater than $20 \mathrm{~mm}$. in $\mathrm{V} 1$, or an $\mathrm{R} / \mathrm{S}$ ratio in V1 less than $0 \cdot 3$. 12-24 months: $R$ wave greater than $36 \mathrm{~mm}$. in V5 or $24 \mathrm{~mm}$. in V6, S wave greater than $27 \mathrm{~mm}$. in $\mathrm{V} 1$ or an R/S ratio in V1 less than 0.5 .

* In infants where an atrial septal defect was present, the mixed venous $\mathrm{O}_{2}$ saturation was estimated to be two-thirds of that in the inferior vena cava plus one-third of that in the superior vena cava. 
TABLE I

PERTINENT CLINICAL AND LABORATORY DATA IN 29 CHILDREN SELECTED FOR PULMONARY ARTERY BANDING

\begin{tabular}{|c|c|c|c|c|c|c|c|c|c|c|}
\hline \multirow{2}{*}{$\begin{array}{l}\text { Case } \\
\text { No. }\end{array}$} & \multirow{2}{*}{$\underset{\text { (mth.) }}{\text { Age }}$} & \multirow{2}{*}{ Sex } & \multirow{2}{*}{ Diagnosis } & \multirow{2}{*}{ Qp/Qs } & \multirow{2}{*}{$\mathbf{P p} / \mathbf{P s}_{\mathbf{s}}$} & \multirow{2}{*}{$\begin{array}{l}\text { Electro- } \\
\text { cardiogram }\end{array}$} & \multicolumn{2}{|c|}{ MPA Pressure } & \multirow{2}{*}{$\begin{array}{l}\text { Year of } \\
\text { operation }\end{array}$} & \multirow{2}{*}{ Outcome } \\
\hline & & & & & & & $\begin{array}{c}\text { Pre- } \\
\text { banding }\end{array}$ & $\begin{array}{c}\text { Post- } \\
\text { banding }\end{array}$ & & \\
\hline $\begin{array}{r}1 \\
2 \\
3 \\
4 \\
5 \\
6 \\
7 \\
8 \\
9 \\
10 \\
11 \\
12 \\
13 \\
14 \\
15 \\
16 \\
17 \\
18 \\
19 \\
20 \\
21 \\
22 \\
23 \\
24 \\
25 \\
26 \\
27 \\
28 \\
29\end{array}$ & $\begin{array}{c}0 \cdot 5 \\
2 \\
1 \\
1 \\
3 \\
9 \\
2 \\
2 \\
7 \\
2 \\
4 \\
2 \\
6 \\
27 \\
3 \\
3 \\
4 \\
13 \\
2 \\
11 \\
12 \\
3 \\
0 \cdot 5 \\
1 \\
6 \\
11 \\
3 \\
1 \\
10\end{array}$ & $\begin{array}{l}\text { M } \\
F \\
\text { M } \\
M \\
F \\
F \\
F \\
F \\
F \\
M \\
M \\
F \\
M \\
F \\
F \\
F \\
M \\
F \\
M \\
F \\
M \\
F \\
F \\
M \\
F \\
F \\
F \\
M\end{array}$ & $\begin{array}{l}\text { VSD } \\
\text { VSD + PDA } \\
\text { VSD + PDA } \\
\text { AV Canal } \\
\text { VSD } \\
\text { VSD } \\
\text { VSD } \\
\text { VSD } \\
\text { VSD } \\
\text { VSD } \\
\text { VSD + PDA } \\
\text { VSD + PDA } \\
\text { VSD + PDA } \\
\text { AV Canal } \\
\text { AV Canal } \\
\text { AV Canal } \\
\text { VSD + PDA } \\
\text { VSD } \\
\text { VSD } \\
\text { VSD } \\
\text { VSD } \\
\text { VSD + PDA } \\
\text { VSD + ASD } \\
\text { VSD + ASD } \\
\text { AV Canal } \\
\text { AV Canal } \\
\text { VSD + ASD } \\
\text { VSD + PDA } \\
\text { VSD }\end{array}$ & $\begin{array}{l}2 \cdot 1 \\
2 \cdot 1 \\
4 \cdot 0 \\
1 \cdot 5 \\
2 \cdot 7 \\
2 \cdot 8 \\
2 \cdot 1 \\
\overline{-} \\
2 \cdot 5 \\
2 \cdot 4 \\
3 \cdot 8 \\
3 \cdot 5 \\
15 \cdot 0 \\
\overline{3 \cdot 3} \\
2 \cdot 4 \\
1 \cdot 2 \\
3 \cdot 8 \\
- \\
1.9 \\
2 \cdot 5 \\
2 \cdot 5 \\
3 \cdot 8\end{array}$ & $\begin{array}{l}1.00 \\
0.80 \\
0.68 \\
0.94 \\
1.00 \\
0.67 \\
0.88 \\
\overline{0.78} \\
0.94 \\
\overline{0.94} \\
0.87 \\
0.97 \\
0.91 \\
0.92 \\
0.84 \\
0.65 \\
0.94 \\
1.00 \\
0.80 \\
- \\
0.60 \\
1.00 \\
0.95 \\
0.81\end{array}$ & $\begin{array}{l}\text { Normal } \\
\text { Normal } \\
\text { Normal } \\
\text { Normal } \\
\text { CVH } \\
\text { CVH } \\
\text { CVH } \\
\text { CVH } \\
\text { CVH } \\
\text { CVH } \\
\text { CVH } \\
\text { CVH } \\
\text { CVH } \\
\text { CVH } \\
\text { CVH } \\
\text { CVH } \\
\text { CVH } \\
\text { CVH+ RV } \\
\text { CVH + RV } \\
\text { RVH } \\
\text { RVH } \\
\text { RVH } \\
\text { RVH } \\
\text { RVH } \\
\text { RVH } \\
\text { RVH } \\
\text { RVH } \\
\text { RVH } \\
\text { RVH }\end{array}$ & $\begin{array}{l}50 \\
60 \\
45 \\
80 \\
40 \\
60 \\
60 \\
80 \\
70 \\
40 \\
80 \\
50 \\
48 \\
50 \\
60 \\
75 \\
70 \\
40 \\
40 \\
\text { Not b } \\
36 \\
45 \\
35 \\
48 \\
104 \\
60 \\
- \\
-\end{array}$ & $\begin{array}{r}23 \\
28 \\
25 \\
38 \\
25 \\
20 \\
20 \\
24 \\
20 \\
26 \\
20 \\
29 \\
34 \\
22 \\
35 \\
23 \\
32 \\
26 \\
35 \\
\text { aded } \\
22 \\
28 \\
18 \\
45 \\
40 \\
\\
\end{array}$ & $\begin{array}{l}1964 \\
1962 \\
1964 \\
1963 \\
1958 \\
1960 \\
1960 \\
1961 \\
1961 \\
1963 \\
1961 \\
1963 \\
1965 \\
1963 \\
1962 \\
1965 \\
1960 \\
1964 \\
1964 \\
1961 \\
1963 \\
1961 \\
1965 \\
1964 \\
1965 \\
1965 \\
1965 \\
1965 \\
1960\end{array}$ & $\begin{array}{l}\text { Improved } \\
\text { Improved } \\
\text { Improved } \\
\text { Improved } \\
\text { Improved } \\
\text { Improved } \\
\text { Improved } \\
\text { Improved } \\
\text { Improved } \\
\text { Improved } \\
\text { Improved } \\
\text { Improved } \\
\text { Improved } \\
\text { Improved } \\
\text { Improved } \\
\text { Improved } \\
\text { Early death } \oint \\
\text { Not improved } \\
\text { Early death } \S \\
\text { Improved } \\
\text { Not improved } \\
\text { Improved } \\
\text { Late death } \dagger \\
\text { Early death } \oint \\
\text { Early death } \oint \\
\text { Late death } \ddagger \\
\text { Early death } \oint . \\
\text { Death on operating table } \\
\text { Death on operating table }\end{array}$ \\
\hline
\end{tabular}

VSD, ventricular septal defect; PDA, patent ductus arteriosus; AV canal, atrioventricular canal; ASD, atrial septal defect.

$\mathrm{Qp} / \mathrm{Qs}$, pulmonary-systemic flow ratio; $\mathrm{Pp} / \mathrm{Ps}$, pulmonary-systemic systolic pressure ratio.

CVH, combined ventricular hypertrophy.

RVH, right ventricular hypertrophy.

* Patient could not tolerate banding so procedure was abandoned after several attempts.

+ Died 2 months after operation.

Died during first post-operative week.

Combined ventricular hypertrophy ${ }^{\star}$, 0-24 months: Voltage requirements for right and left ventricular hypertrophy, voltage requirements for right or left ventricular hypertrophy, and relatively large voltages (greater than $80 \%$ of voltage requirement) for the other ventricle or equiphasic QRS complexes (greater than $60 \mathrm{~mm}$.) in the mid-præcordial leads.

The operative procedure consisted of constricting the main pulmonary artery with umbilical tape to approximately one-third of its original sizet. The effectiveness of the band was evaluated by open-chest pressure measurements in the pulmonary artery and right ventricle before and after the procedure. In each case, the aim was to reduce the pulmonary arterial pressure by 50 per cent or more. In those patients who developed persistent bradycardia, lesser degrees of constriction were accomplished.

All patients who died were brought to necropsy. Since microscopical study of the pulmonary vasculature was limited in each patient to only 10 or 15 vessels, these

* Right ventricular dominance was assumed to be present when evidence for right ventricular hypertrophy was appreciably greater than that for left ventricular hypertrophy.

† Performed by Dr. J. V. Maloney, Jr., Dr. D. G. Mulder, and Dr. P. G. Gaal. data are not included in the present report. According to Wagenvoort (1960), great numbers of arteries (as many as 196) must be analysed to appraise accurately the status of the pulmonary vascular bed.

\section{RESULTS}

The over-all mortality rate was 31 per cent. The differences in mortality rate cannot be attributed to the age of the infant or to changes in operative management. The mean age of the subjects in the

\section{TABLE II}

RELATION OF MORTALITY OF PULMONARY BANDING TO ANATOMICAL LESIONS

\begin{tabular}{|c|c|c|c|c|}
\hline \multirow[t]{2}{*}{ Diagnosis } & \multirow{2}{*}{$\begin{array}{l}\text { No. of } \\
\text { patients }\end{array}$} & \multicolumn{2}{|c|}{ Deaths } & \multirow{2}{*}{$\begin{array}{c}\text { Total } \\
\text { mortality }\end{array}$} \\
\hline & & Early & Late & \\
\hline \multirow{3}{*}{$\begin{array}{l}\text { Ventricular septal defect } \\
\text { Ventricular septal defect and } \\
\text { patent ductus arteriosus } \\
\text { Ventricular septal defect and } \\
\text { atrial septal defect } \\
\text { Atrio-ventricular canal }\end{array}$} & 12 & 2 & 0 & 2 \\
\hline & 8 & 2 & 0 & 2 \\
\hline & $\begin{array}{l}3 \\
6\end{array}$ & $\begin{array}{l}2 \\
1\end{array}$ & $\begin{array}{l}1 \\
1\end{array}$ & $\begin{array}{l}3 \\
2\end{array}$ \\
\hline Totals & 29 & 7 & 2 & 9 \\
\hline
\end{tabular}


high mortality group (6.1 months) was actually greater than that in the low mortality group (4.6 months). In the high mortality group, 8 of the 12 operations were performed in 1964 and 1965, whereas in the low mortality group, only 4 of the 17 operations were performed during these years. No relation could be demonstrated between the pulmonary-systemic pressure or flow ratios and the findings on electrocardiogram or to the survival of the infant.

A close association of certain features of the electrocardiogram and the ultimate outcome of the operation was found in most cases (Table III). Only one of the 17 infants with combined ventricular hypertrophy, left ventricular hypertrophy, or normal tracings died. However, two-thirds of the 12 patients in whom there was pure right ventricular hypertrophy or combined ventricular hypertrophy with right ventricular dominance died. Of the 4 survivors in this group, one could not tolerate

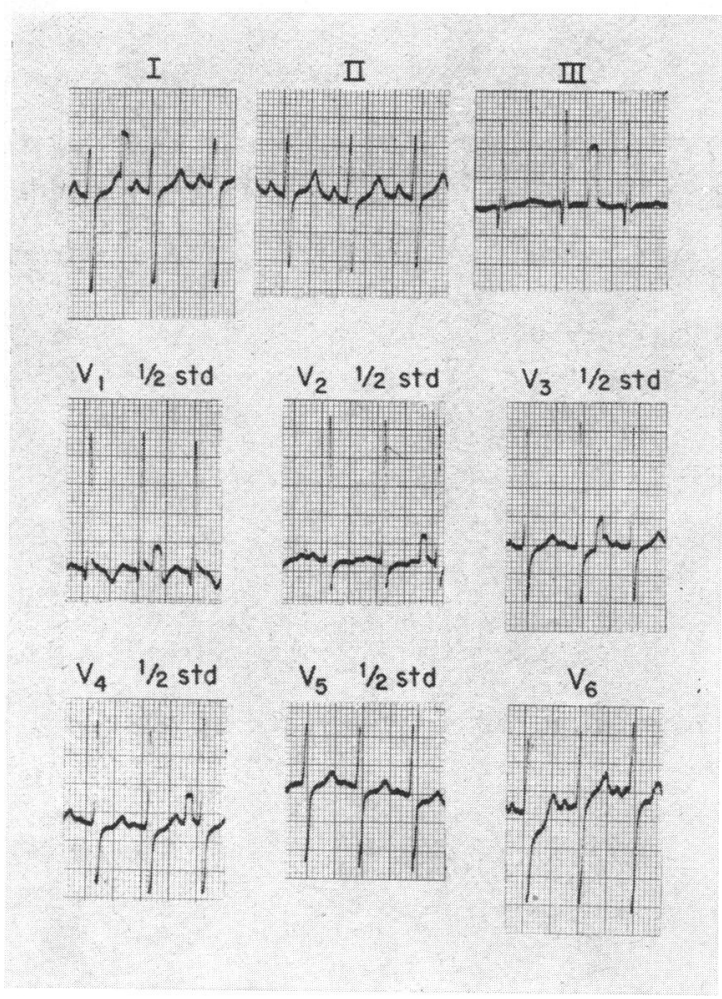

FIG. 1.-Electrocardiogram showing evidence of severe right ventricular hypertrophy in a 1-year-old infant with a ventricular septal defect (Case 21). Note the $R$ wave in $V 1$ of $48 \mathrm{~mm}$., the deep $17 \mathrm{~mm}$. S wave in V6, and normal amplitude $R$ waves in V5 and V6. Banding of the pulmonary artery in this case could not be accomplished. Each attempt was followed by severe bradycardia.
TABLE III

RELATION OF MORTALITY OF PULMONARY ARTERY BANDING TO ELECTROCARDIOGRAPHIC EVIDENCE OF RIGHT VENTRICULAR DOMINANCE

\begin{tabular}{|c|c|c|c|c|c|}
\hline \multirow{2}{*}{ Electrocardiogram } & \multirow{2}{*}{$\begin{array}{c}\text { No. of } \\
\text { patients }\end{array}$} & \multirow{2}{*}{$\begin{array}{c}\text { Age } \\
\text { (mth.) } \\
\text { (mean) }\end{array}$} & \multicolumn{2}{|c|}{ Deaths } & \multirow{2}{*}{$\begin{array}{c}\text { Total } \\
\text { mortality }\end{array}$} \\
\hline & & & Early & Late & \\
\hline \multirow{2}{*}{$\begin{array}{l}\text { Dominant RVH } \\
\text { (with or without } \\
\text { LVH) } \\
\text { No dominant RVH } \\
\text { (CVH, LVH or } \\
\text { normal) }\end{array}$} & 12 & $6 \cdot 1$ & 6 & 2 & 8 \\
\hline & 17 & $4 \cdot 6$ & 1 & 0 & 1 \\
\hline
\end{tabular}

RVH, LVH, CVH; right, left, or combined ventricular hypertrophy.

any narrowing of the pulmonary artery and so the procedure was abandoned (Case 21, Table I). The electrocardiogram of this infant is shown in Fig. 1. A second child showed a pulmonary artery pressure reduction of only $8 \mathrm{~mm} . \mathrm{Hg}$, and at recatheterization two weeks later, no systolic gradient at all could be demonstrated across the pulmonary valve (Case 18, Table I). The electrocardiogram of this child is shown in Fig. 2.

The close association of right ventricular dominance and failure to survive was found to be of statistical significance. Analysis of the two groups of infants (those with and those without electrocardiographic evidence of right ventricular dominance) revealed a highly significant difference in the mortality rates $(p<0.001)$.

The presence of a complicating defect affected the outcome significantly only when the associated lesion was an atrial septal defect. Since all three of these children were in the group with right ventricular dominance, this could have accounted in part for the higher mortality rate of that group. However, even if these three are excluded, the mortality rate remains very high and is significantly greater than in the group with no right ventricular dominance $(\mathrm{p}<0.005)$.

\section{Discussion}

It is generally agreed that banding of the pulmonary artery may be a lifesaving procedure in selected cases. The present data confirm the impression of Verney (1964) that the pulmonarysystemic pressure ratio is not a helpful parameter for selection of candidates for this operation. Likewise, pulmonary-systemic flow ratios determined by currently available methods are of limited value. Their deficiency probably stems from errors arising from the following factors: (1) poor mixing of venous blood in the right atrium, (2) poor mixing of venous blood in the pulmonary artery when a high ventricular septal defect is present, and (3) intra- 


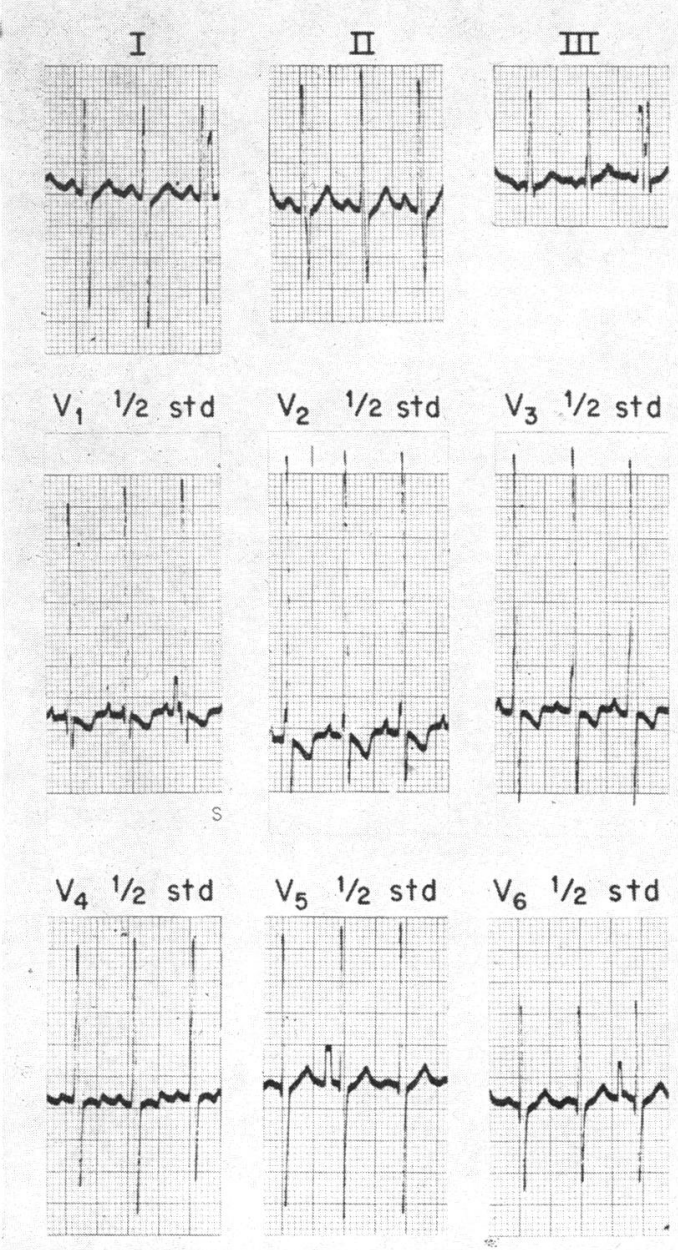

FIG. 2.-Electrocardiogram showing evidence of combined ventricular hypertrophy with right ventricular dominance as manifested by the $65 \mathrm{~mm}$. R wave in $V 1$ and $30 \mathrm{~mm}$. $R$ wave in V6. No functional constriction of the pulmonary artery was achieved in this 1-year-old child with a ventricular septal defect (Case 18).

pulmonary right-to-left shunts due to pulmonary congestion and atelectasis.

The importance of the electrocardiogram in the pre-operative evaluation of candidates for pulmonary banding has not been previously stressed. The only reported correlation of the electrocardiogram with mortality rate is contained in a report by Gammelgaard et al. (1961): these authors found that one child with a normal tracing and another with left ventricular hypertrophy recovered, whereas one with right ventricular hypertrophy died after the operation. Their remaining 20 patients all had combined ventricular hypertrophy and in this group there were 6 deaths. The criteria for chamber enlarge- ment were not given and the presence of ventricular dominance in combined ventricular hypertrophy was not mentioned.

The present data suggest that the electrocardiogram is a very reliable indicator of the response to be expected from operation. The presence of right ventricular dominance probably reflects a significant degree of peripheral pulmonary vascular obstruction in most cases. This can be functionally equated with banding of the pulmonary artery and attempts to band the main pulmonary artery further under these circumstances would be expected to increase the risk at operation. Although additional immediate or long-term benefits might be obtained, the margin of safety is narrowed and even minimal constriction of the pulmonary artery could cause hypoxæmia with bradycardia or cardiac arrest. This was dramatically illustrated in Cases 21,28 , and 29.

Because of the wide range of voltage values in normal children, electrocardiographic evidence of right ventricular dominance per se cannot be considered an absolute contraindication to pulmonary banding in a given case. This is illustrated by Cases 20 and 22, both of which had evidence of pure right ventricular hypertrophy on electrocardiogram but showed definite and immediate improvement following operation. However, the presence of right ventricular dominance on electrocardiogram should alert the cardiologist to the possibility of some other complicating condition or to the need for a further trial of conservative management. If operation is performed, the surgeon should be apprised of the increased risk of bradycardia and cardiac arrest at the time of banding. He should be further advised that repeated attempts to constrict the pulmonary artery under these circumstances are not warranted.

\section{SUMMARY AND CONCLUSIONS}

The laboratory and clinical data of 29 children with left-to-right ventricular shunts requiring pulmonary artery banding to alleviate cardiac failure were reviewed. The electrocardiogram was found to be a good index of the operative risk. Of the 17 children without right ventricular dominance, 16 survived the operation. Of the 12 children with right ventricular dominance, only 4 survived.

The results of this investigation indicate that banding of the pulmonary artery in the presence of electrocardiographic evidence of pulmonary vascular disease (right ventricular dominance) is associated with a prohibitive fatality rate. The risk under these conditions is greater than one would expect with definitive repair. This demands a critical review of one of the proposed indications 
for operation: namely, that it be performed to prevent progression of pulmonary vascular disease. Although this may, indeed, be one of the beneficial by-products of the procedure, pulmonary vascular disease does not constitute justification for surgical palliation and, in fact, may be against it. In the authors' opinion, the sole indication for the operation is congestive heart failure which does not respond to an adequate trial of conservative therapy.

\section{REFERENCES}

Albert, H. M., Fowler, R. L., Craighead, C. C., Glass, B. A., and Atik, M. (1961). Pulmonary artery banding. A treatment for infants with intractable cardiac failure due to interventricular septal defects. Circulation, 23, 16.

Craig, T. V., and Sirak, H. D. (1963). Pulmonary artery banding. . An analysis of 38 cases. $\mathcal{F}$. thorac. cardiovasc. Surg., 45, 599.

Dammann, J. F., Jr., McEachen, J. A., Thompson, W. M., Jr., Smith R., and Muller, W., H., Jr. (1961). The re- gression of pulmonary vascular disease after the creation of pulmonary stenosis. $\mathcal{F}$. thorac. cardiovasc. Surg., 42, 722.

Gammelgaard, A., Therkelsen, F., Boesen, I., and Terslev, E. (1961). Ventricular septal defects in infancy treated with surgical narrowing of the pulmonary artery. Acta chir. scand., Suppl. 283, p. 84.

Goldblatt, A., Bernhard, W. F., Nadas, A. S., and Gross, R. E. (1965). Pulmonary artery banding. Indications and results in infants and children. Circulation, 32, 172.

Guntheroth, W. G. (1965). Pediatric Electrocardiography. Normal and Abnormal Patterns, Incorporating the Vector Approach, p. 27. W. B. Saunders, Philadelphia.

Muller, W. H., Jr., and Dammann, J. F., Jr. (1952). The treatment of certain congenital malformations of the heart by the creation of pulmonic stenosis to reduce pulmonary hypertension and excessive pulmonary blood flow. Surg. Gynec. Obstet., 95, 213.

Verney, R. (1964). Indications du banding de l'artère pulmonaire dans les communications interventriculaires du nourrisson. Ann. Proc. Assoc. Eur. Pad. Cardiologist, $1,17$.

Wagenvoort, C. A. (1960). Vasoconstriction and medial hypertrophy in pulmonary hypertension. Circulation 22, 535. 